\title{
Dual-mobility cup: a new French revolution
}

\author{
Jacques Henri Caton $^{1} \cdot$ André Ferreira $^{2}$ (D)
}

Received: 17 January 2017 / Accepted: 26 January 2017 / Published online: 14 February 2017

(C) SICOT aisbl 2017

When we (Figs. 1 and 2) began performing total hip arthroplasty (THA) 40 years ago, in 1976, we used the current gold standard for hips, the LFA (low-friction arthroplasty), developed by Sir John Charnley in 1962. However, the same year the dual-mobility cup (DMC) was born and patented.

More than 40 years later, results with standard cups were satisfactory [1] but had two long-term problems, polyethylene (PE) wear and dislocations with an increased

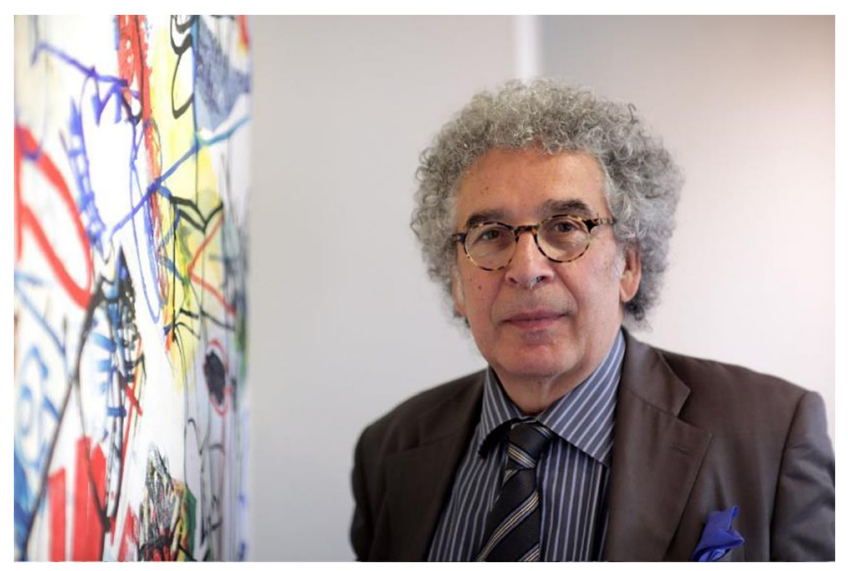

Fig. 1 Jacques H. Caton, MD, guest editor

André Ferreira

a.ferreira@cliniqueduparclyon.com

Jacques Henri Caton

caton.jacques@wanadoo.fr

Institut Orthopédique, 103 rue Coste, 69300 Caluire, France

2 Clinique du Parc, 155 Ter Boulevard de Stalingrad, 69006 Lyon, France

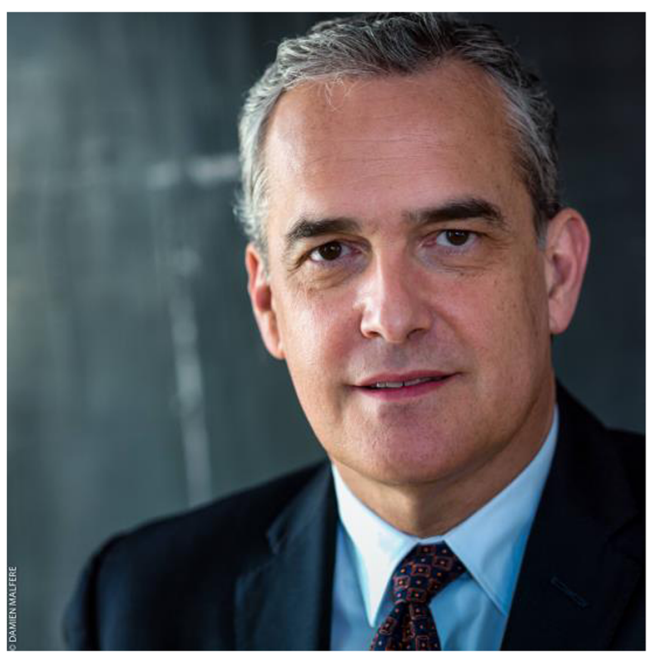

Fig. 2 André Ferreira, MD, guest editor

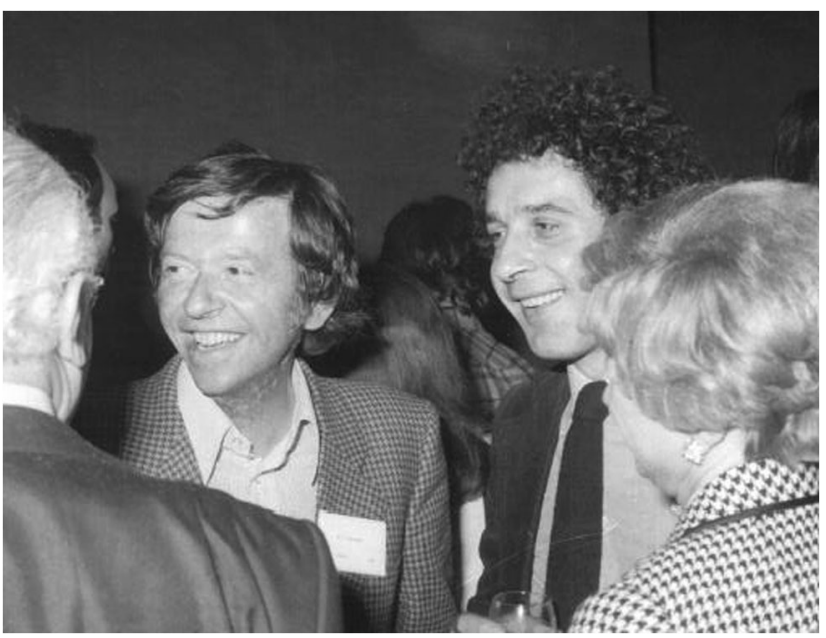

Fig. 3 Pr. Gilles Bousquet and Dr. Jacques H. Caton, MD (1979) 


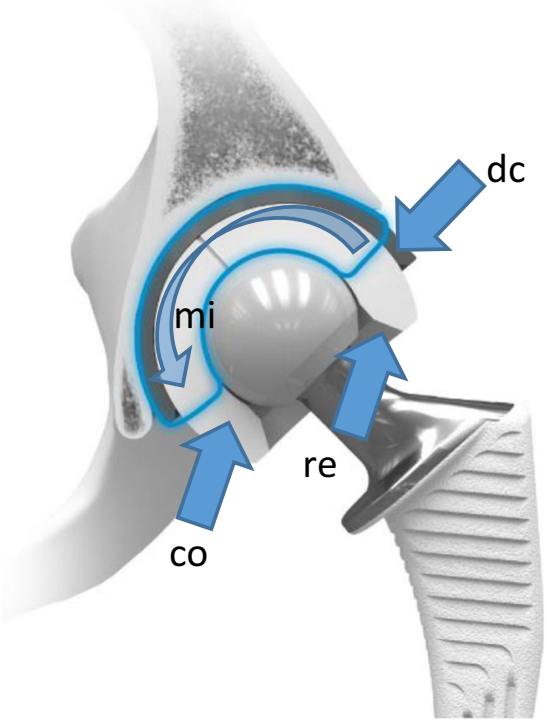

Fig. 4 Contemporary and dual-mobility cup (DMC): cup design (dc), insert mobility (mi), insert cover (co), retention system (re) and risk of contact with the neck (courtesy T. Aslanian [14])

cumulative risk of $>1-1.38 \%$ each 5 years, leading to recurrent instability $[2,3]$. Dislocations remain the major risk factor following both primary and revision THA [4, 5]. However, the situation is different in France, and for ten years, from 2005 to 2014, the dislocation rate following total THA decreased from 9 to 6\% [6]. Why this "new" French paradox?

In the 1970s, Gilles Bousquet (Fig. 3) and his engineer André Rambert had the genius idea of marrying the LFA and its longevity benefits to the large heads (metal-metal) of Mac KEE FARRAR, providing greater stability. In 1979, based on this concept, the idea of a dual-mobility cup (DMC) was born [7]. The scope of this concept was to decrease the dislocation rate of a new cup by associating two articulating surfaces: one large (outer surface inside a metallic cup), and one smaller (inner surface, between femoral head and insert retentiverim) both coupling metal and polyethylene. Results confirmed that DM concept gives increased jumping distance [8] and better range of motion (ROM) in patients following THA.

Indeed, the DMC has the advantages of a large head with an increase stability but without adverse effects like trunnionosis, thin $\mathrm{PE}$, thin ceramic acetabular insert or noises and squeaking [9] often found in ceramic-onceramic bearings. Initial results, published by Bousquet et al. in 1986, showed satisfactory midterm results and a low dislocation rate of $2.8 \%$ in 112 THA revisions [10]. However, more than 30 years after this article, discussion remains regarding the optimal method for reducing THA dislocation rate [11] despite the positive long-term results obtained with the DMC [3]. Even long-term results of the first-generation Bousquet cup [12] are respectable, with a 25-year survival rate comparable with similar uncemented series and with the major advantage of a greatly reduced dislocation rate as well as patients under 50 years old [13] than for the older ones [12].

Over the last 20 years, the DMC concept has evolved [8], so that from the first Novae cup to contemporary cups, many designs have been available; however, not all DMC are alike [14] in particular for the shape of the cup, the inner polish, the insert design, the retentive rim (third articulation) and its flanges (Fig. 4). For example topology surface: the press-fit cementless DMC using a bilayer coating (Fig. 5), as in the standard cups, should hope to prove efficient in regards to long-term cup fixation [9]. On the other hand, cemented DMCs are commonly used in revision and sometimes in primary THA using different techniques [15].

Hamadouche [15] reported that DMC sockets represent the best option for treating THA instability, which is confirmed by the Swedish Hip Arthroplasty Register (SHAR) [16] after a case-control comparative study of 355 revisions due to dislocation performed with a standard cemented cup (head size 28 or $36 \mathrm{~mm}$ ) vs. 436 Avantage $^{\mathrm{TM}}$ cemented DMCs: second revision for recurrent dislocation in DMC groups was $1.6 \%$ vs. $6.8 \%$ after standard cups; at midterm follow-up, re-revision for any reason was necessary in $14 \%$ of standards cups vs. $6.4 \%$ of DMCs. In the Lithuanian register, results are comparable in favour of cemented DMC [17] (Avantage ${ }^{\mathrm{TM}}$ cup) vs. cemented standard fixed cups (Exeter ${ }^{\mathrm{TM}}$ ).

Fessy et al. [18] assessed 344 THA revisions performed with a cementless DMC between 2005 and 2011 and showed its advantages for all revision indications and for treating recurrent dislocation after aseptic loosening.
Fig. 5 Bilayer coating (courtesy A. Ferreira, T. Aaslanian [9])

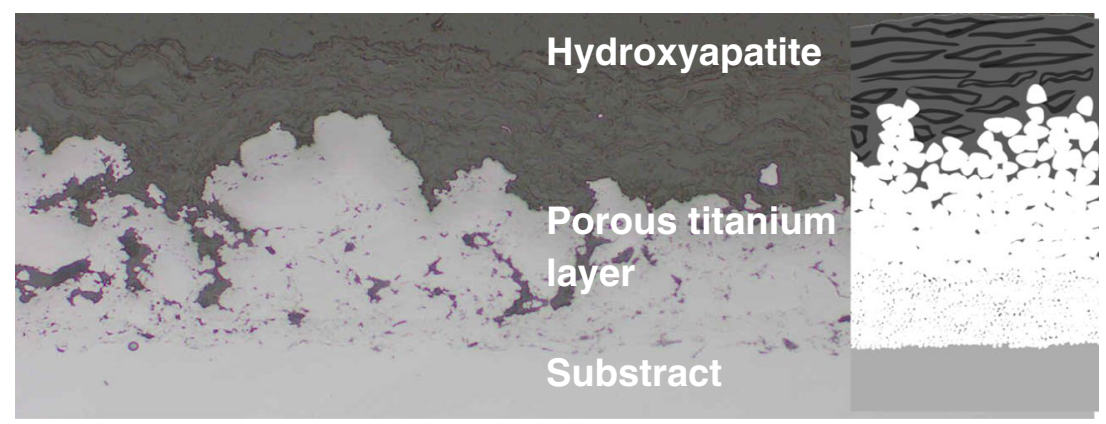


Fig. 6 Dual-mobility cup (DMC) survivorship: $98.4 \%$ [95\% confidence interval (95.3-100)] (courtesy Puch et al. [25])

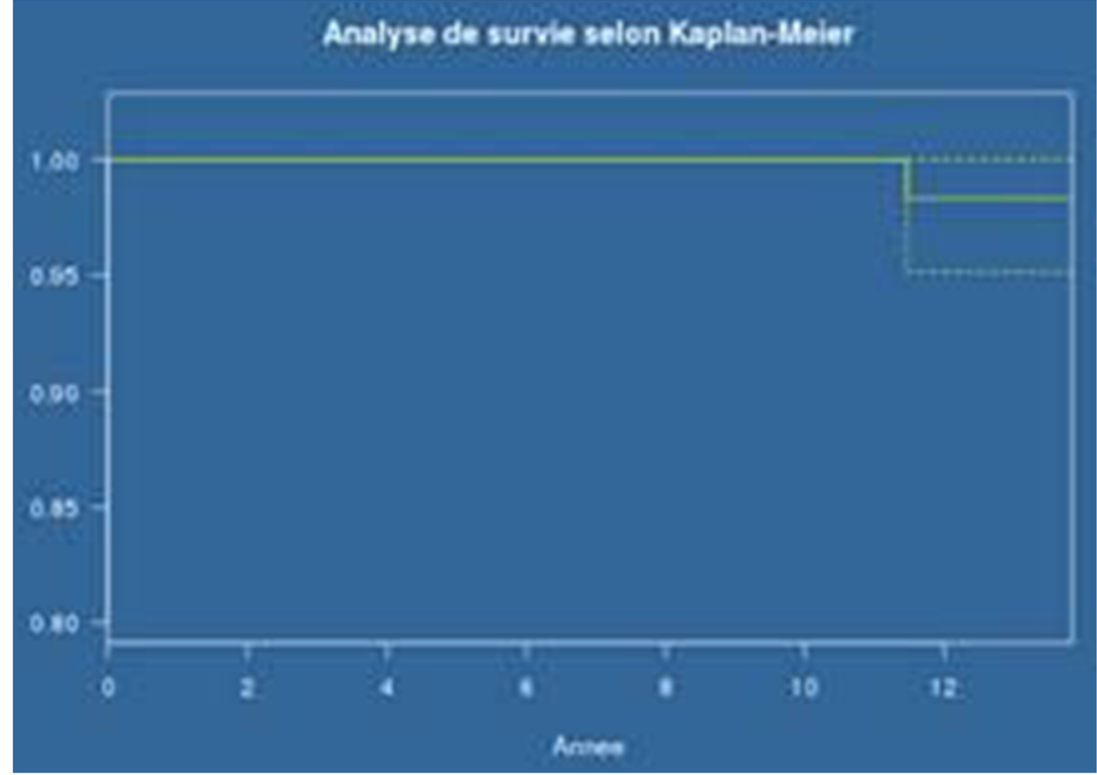

These results were confirmed by the French Orthopaedic Society (SOFCOT) matched case-control study comparing DMC and standard cups in revision for any reason [19].

Good results are also established for specific categories of patients requiring a THA: those with femoralhead osteonecrosis [20], the obese [21], patients with high risk of dislocation (younger, active individuals) [22], or after hip fractures [23]. Regardless, taking in account the efficiency of DMC against instability, its use even with hip musculoskeletal oncology is emphasised by Zocalli et al. [24].

DMC in THA is becoming more and more popular among orthopaedic surgeons and is also being performed in a

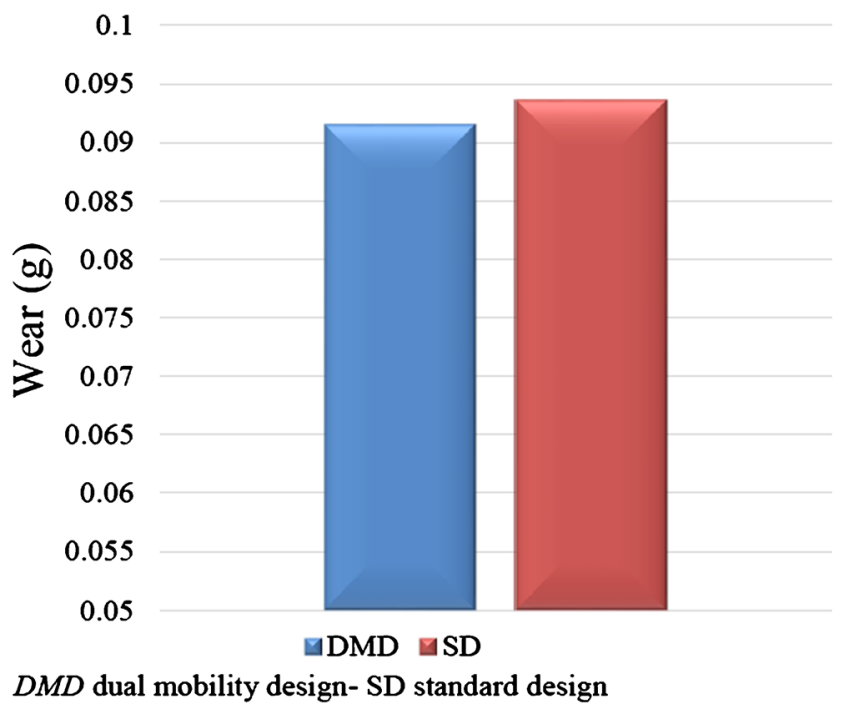

Fig. 7 Comparative gravimetric wear between dual-mobility (DMC) and standard cups (courtesy Gaudin et al. [29]) younger population $[<55$ years old], with datas more than ten years' follow-up showing a high survival rate (98.4\%) (Fig. 6), equal to those of the oldest population [25]. In this series (Gyros cup), only one failure was observed, due to aspetic loosening in a 55-year-old patent, at 14 years' follow-up. At long-term follow-up, aseptic cup loosening and intra-prosthetic dislocation (IPD) due to wear remained the primary complications [26]. It makes sense that for the young population demanding high-implant prosthetic performance, using highly cross-linked polyethylene (HXLPE) may reduce wear [27] but without defintive proof for the moment.

Wear remains a significant problem mainly for firstgeneration designs [28]. In fact, different studies showed at least equivalent wear between DMC and standard cups (in vitro study) [29] (Fig. 7); however, it is necessary to understand wear mechanism and location [28]. This is allowed by studying wear patterns on first-generation explants [30]: indeed, there is not only wear on outer and inner articulations but also on the third one between stem neck and insert rim [7]. Linear penetration rate is therefore ineffective for estimating wear of dual-mobility inserts, since its wear is not two- but three-dimensional [31]. This observation shows it is necessary to avoid large-diameter or rough femoral necks, which increase the risk of impingement and wear on the retentive rim. For the same reasons, it is important that the Morse taper stem is fully engaged with the femoral prosthetic head.

Choosing a femoral component with a thin, round and highly polished neck, like Charnley's one, is very important to prevent IPD, as contemporary DMC results show [32]. Is, then, HXLPE a safe alternative and able to play a role in preserving this retentive rim from cracks after introducing the head [33]? Let's see... 


\section{Cumulated number of published articles on the dual mobility cup according to the publication year and the country of origin.}

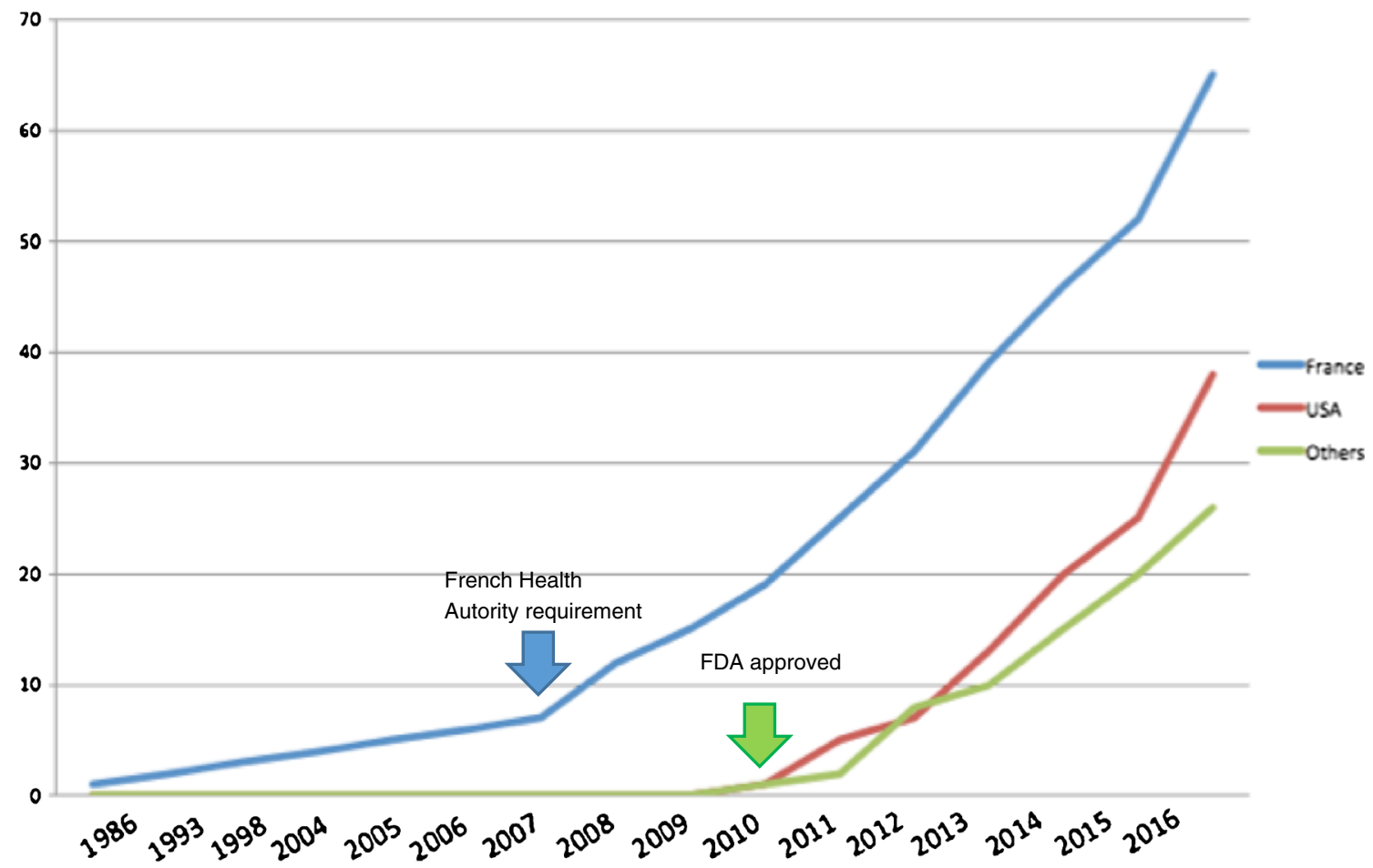

Fig. 8 Evolution of the numbers of publications about the DMC for 30 years. (courtesy Caton)

DMC implantation began in France, spread to other European countries, and appeared on the USA market in 2009 following US Food and Drug Administration (FDA) approval. Its use increased in both populations, young and old, regardless of approach (posterolateral; direct anterior [23, 34]; Röttinger [35]), with increasingly positive results being reported in an increasing number of publications [6] (Fig. 8).

Are the LFA and the DMC [32] the new gold standard? There is a need for long-term clinical evidence and a necessity to establish a register for contemporary DMC, as described by Ferreira et al. [5], to better understand whether all patients needing a THA will benefit from this revolutionary implant.

\section{Compliance with ethical standards}

\section{Conflict of interest}

Caton J.H.

- SICOT Hip and Publications chairman

- International Orthopaedics: Associate Editor

- SICOT-J: Chief editor

- Royaties from Groupe Lépine and Ceraver

Ferreira A.

- SICOT Hip: co-chairman

- SICOT-J: associate editor

- Royalties from Groupe Lépine and Lima Corporate

\section{References}

1. Caton J, Prudhon JL (2011) Over 25 years survival after Charnley's total hip arthroplasty. Int Orthop 35:185-188

2. Berry DJ, Von KM, Schlec CD, Armsen WS (2004) The cumulative long term risk of dislocation after primary Charnley THA. J Bone Joint Surg Am 86-A:9-14

3. Caton JH, Aslanian T, Prudhon JL, Ferreira A, Dehri G, Puch JM (2016) Dual mobility cup : a new THA revolution. e-mémoire Académie Nationale de Chirurgie 004-010. doi: 10.14607/ emem.2016.1.004

4. Falez F, Papalia M, Favetti F, Panegrossi G, Casella F, Mazzotta G (2016) Total hip arthroplasty instability in Italy. doi: 10.1007/ s00264-016-3345-6

5. Ferreira A, Prudhon JL, Verdier R, Puch JM, Descamps L, Dehri G, Remi M, Caton JH (2017) Contemporary Dual Mobility Cup. A regional and private register: methodology and results. Int Orthop. doi:10.1007/s00264-017-3405-6

6. Batailler C, Fary C, Verdier R, Aslanian T, Caton J, Lustig S (2016) The evolution of outcomes and indications for the dual-mobility cup: a systematic review. Int Orthop. doi:10.1007/s00264-0163377-y

7. Noyer D, Caton JH (2016) Once upon a time.... Dual mobility: history. Int Orthop. doi:10.1007/s00264-016-3361-6

8. Guyen O (2016) Dual mobility cups provide biomechanical advantages in situation at risk for dislocation: a finite element analysis. Int Orthop. doi:10.1007/s00264-016-3368-z

9. Ferreira A, Aslanian T, Dalin T, Picaud J (2016) Ceramic bearings with bilayer coating in cementless total hip arthroplasty. A safe solution. A retrospective study of one hundred and twenty six cases with more than ten years' follow-up. Int Orthop. doi:10.1007/ s00264-016-3271-7

Funding No funding sources. 
10. Bousquet G, Argenson C, Godeneche JL, Cisterne JP, Gazielly DF, Girardin P, Debiesse JL (1986) Recovery after aseptic loosening of cemented total hip arthoplasties with Bousquet's cementless prosthesis : a propos of 136 cases. Rev Chir Orthop Reparatrice Appar Mot 72(2):70-4

11. Zagra L, Caboni E (2016) THA instability treatment without dual mobility cup: brief overview and experience of other option. Int Orthop. doi:10.1007/s00264-016-3383-0

12. Neri T, Philippot R, Farizon F, Boyer B (2016) Results of primary total Hip replacement with first generation Bousquet dual mobility socket with more than 25 years follow up. About a series of 212 hips. Int Orthop. doi:10.1007/s00264-016-3373-2

13. Philippot R et al (2016) Dual mobility socket for patient Under 50 years old. More than 20 years follow up of 131 hips. Int Orthop. doi:10.1007/s00264-016-3585-y

14. Aslanian T (2016) All dual mobility cups are not the same. Int Orthop. doi:10.1007/s00264-016-3380-3

15. Hamadouche M, Ropars M, Rodaix C, Musset T, Gaucher F, Biau D, Courpied JP, Huten D (2016) Five to thirteen year results of a cemented dual mobility socket to treat recurrent dislocation. Int Orthop. doi:10.1007/s00264-016-3343-8

16. Mohaddes M, Cnudde P, Rolfson O et al (2017) Use of dual mobility Cup in revision Hip arthroplasty reduces the risk for further dislocation analysis of 791 first time revisions performed due to dislocation reported to the swedish Hip arthroplasty register. Int Orthop. doi:10.1007/s00264-016-3381-2

17. Tarasevicius S, Smailys A, Grigaitis K et al (2017) Short term outcome after THA using dual mobility cup. Report from Lithuanian Arthroplasty Register. Int Orthop. doi:10.1007/ s00264-016-3389-7

18. Viste A, Desmarchelier R, Fessy MH (2016) Dual mobility cups in revision total hip arthroplasty. Int Orthop. doi:10.1007/s00264-0163363-4

19. Prudhon JL, Desmarchelier R, Hamadouche M, Delaunay C, Verdier R, SoFCOT (2016) Causes for revision of dual-mobility and standard primary total hip arthroplasty: matched case-control study based on a prospective multicenter study of two thousand and forty four implants. Int Orthop. doi:10.1007/s00264-015-3064-4

20. Martz P, Maczynski A, Elsair S, Labattut L, Viard B, Baulot E (2016) Total hip arthroplasty with dual mobility cup in osteonecrosis of the femoral head in young patients: over ten years of follow-up. Int Orthop. doi:10.1007/s00264-016-3344-7

21. Hernigou P, Auregan JC, Potage D, Roubineau F, Flouzat Lachaniette CH, Dubory A (2016) Dual-mobility implants prevent hip dislocation following hip revision in obese patients. Int Orthop. doi:10.1007/s00264-016-3316-y

22. Assi C, Najjar E, Samaha C, Yammine K (2016) Outcomes of dual mobility cups in a young Middle Eastern population. Int Orthop. doi:10.1007/s00264-016-3390-1

23. Homma Y, Baba T, Ozaki Y, Watari T, Kobayashi H, Ochi H, Matsumoto M, Kaneko K (2016) In total hip arthroplasty via the direct anterior approach, a dual-mobility cup prevents dislocation as effectively in hip fracture as in osteoarthritis. Int Orthop. doi:10. 1007/s00264-016-3332-y

24. Zoccali C, Attala D, Scotto di Ucio A, Luzzati A, Biagini R (2017) The Dual Mobility cup in muscular skeletal oncology: rational and indications. Int Orthop. doi:10.1007/s00264-017

25. Puch JM, Derhi G, Descamps L, Verdier R, Caton JH (2016) Dualmobility cup in total hip arthroplasty in patients less than fifty five years and over ten years of follow-up: a prospective and comparative series. Int Orthop. doi:10.1007/s00264-016-3325-x

26. Hernigou P, Dubory A, Potage D, Roubineau F, Flouzat Lachaniette CH (2016) Dual-mobility arthroplasty failure: a rationale review of causes and technical considerations for revision. Int Orthop. doi:10. 1007/s00264-016-3328-7

27. Epinette JA, Harwin SF, Rowan FE, Tracol P, Mont MA, Chughtai M, Westrich GH (2016) Early experience with dual mobility acetabular systems featuring highly cross-linked polyethylene liners for primary hip arthroplasty in patients under fifty five years of age: an international multi-centre preliminary study. Int Orthop. doi:10.1007/s00264-016-3367-0

28. Laura AD, Hothi H, Battisti C, Cerquiglini A, Henckel J, Skinner J, Hart A (2016) Wear of dual-mobility cups: a review article. Int Orthop. doi:10.1007/s00264-016-3326-9

29. Gaudin G, Ferreira A, Gaillard R, Prudhon JL, Caton JH, Lustig S (2016) Equivalent wear performance of dual mobility bearing compared with standard bearing in total hip arthroplasty: in vitro study. Int Orthop. doi:10.1007/s00264-016-3346-5

30. Boyer B, Neri T, Geringer J, Di Iorio A, Philippot R, Farizon F (2016) Understanding wear in dual mobility total hip replacement: first generation explant wear patterns. Int Orthop. doi:10.1007/ s00264-016-3362-5

31. Boyer B, Neri T, Di Lorio A, Geringer J, Philippot R, Farizon F (2017) The linear penetration rate is not relevant for evaluating wear of dual mobility cups: an explant study. Int Orthop. doi:10.1007/ s00264-017-3406-5

32. Prudhon JL, Verdier R, Caton JH (2016) Low friction arthroplasty and dual mobility cup: a new gold standard. Int Orthop. doi:10. 1007/s00264-016-3375-0

33. Malatray M, Roux JP, Gunst S, Pibarot V, Wegrzyn J (2016) Highly crosslinked polyethylene: a safe alternative to conventional polyethylene for dual mobility cup mobile component. A biomechanical validation. Int Orthop. doi:10.1007/s00264-016-3334-9

34. Batailler C, Fary C, Batailler P, Servien E, Neyret P, Lustig S (2016) Total hip arthroplasty using direct anterior approach and dual mobility cup: safe and efficient strategy against post-operative dislocation. Int Orthop. doi:10.1007/s00264-016-3333-x

35. Martz P, Bourredjem A, Laroche D, Arcens M, Labattut L, Binquet C, Maillefert JF, Baulot E, Ornetti P (2016) Röttinger approach with dual-mobility cup to improve functional recovery in hip osteoarthritis patients: biomechanical and clinical follow-up. Int Orthop. doi: 10.1007/s00264-016-3245-9 